\title{
Energy from municipal solid waste
}

\author{
E. C. Rada \\ Department of Civil, Environmental and Mechanical Engineering, \\ University of Trento, Italy
}

\begin{abstract}
This paper presents an overview of the solutions available for obtaining energy from municipal solid waste. Special waste is not taken into account because of its extreme variability of characteristics from region to region and from type to type. On the contrary, municipal solid waste shows aspects useful for a more homogeneous analysis of international interest concerning the exploitation of its energy content. The first part of this paper deals with the evolution of the interest towards energy recovery from municipal solid waste. The analysis is performed at an international level, but a zoom is presented referring to the European Union. The second part of the paper concerns the energy availability taking into account the dynamics of qualitative and quantitative composition of municipal solid waste. The third part analyses the role of selective collection in the frame of energy recovery. In this case it is pointed out how food waste selective collection can change the approach of biogas exploitation: from a landfill based concept (with sanitary landfill seen as a bioreactor) to a reactor based scenario (where the anaerobic digester allows for the collection of $100 \%$ of the biogas generated). The fourth section of the paper concerns the trend in residual municipal solid waste exploitation, taking into account the effects of the European Union directives on the energy recovery strategies and the role played by the Directive 1999/31/CE (a compulsory pre-treatment makes less interesting the option of landfilling, moving the energy exploitation of residual municipal solid waste towards thermal treatments). Finally, a section of this paper concerns a case study that offers a vision on how much anaerobic digestion and thermal treatments can support the energy demand of a citizen.
\end{abstract}

Keywords: anaerobic digestion, biogas, energy, MSW, selective collection, $R D F / S R F$, thermal treatments. 


\section{Introduction}

Municipal Solid Waste (MSW) management has been always a topic much studied and discussed during the years from many points of views and all over the world: production, treatment, management and disposal [1-6] are faced with a growing interest when a country follows the pathway of the optimisation of the environmental management. In the last years the connection between MSW and energy has become very important for a sustainable development, as written in the Rio declaration in 1992 and up-dated in 2012 through the "Rio+20" Earth Summit. In order to achieve this aim, society must reduce the use of the primary resources, specially the not renewable ones, and increase the use of the second resources (materials from recycling stages and residual wastes) [7].

The European Union (EU) targets for 2020 is that $20 \%$ of the energy need in a European country must come from renewable energy and half of this need must be covered by biomass. The Directive 2009/28/CE established that the organic fraction of MSW and the biogas produced and exploited from MSW are considered biomass and energy from biomass respectively.

In this frame, waste results the cheapest resource being always produced in all the life cycle of materials: from the extraction stage (mining waste) to the production and distribution (industrial, hazardous and packaging waste), consumption (MSW, waste from electric and electronic equipment) and treatments (slag and ash). Special waste is not taken into account in this paper because of its extreme variability of characteristics from region to region and from type to type. On the contrary, MSW allows a more homogeneous analysis of international interest concerning the exploitation of its energy content. MSW can be used in different plants directly or after some pre-treatments in order to generate: electric and thermal energy or biofuels [8-13].

The energy content of the waste and its exploitation became one of the main topics of the international research in the last decades. In Figure 1 the number of papers published in the Scopus Data-base in the last 30 years is reported, taking into account the ones on MSW and the ones on MSW and energy.

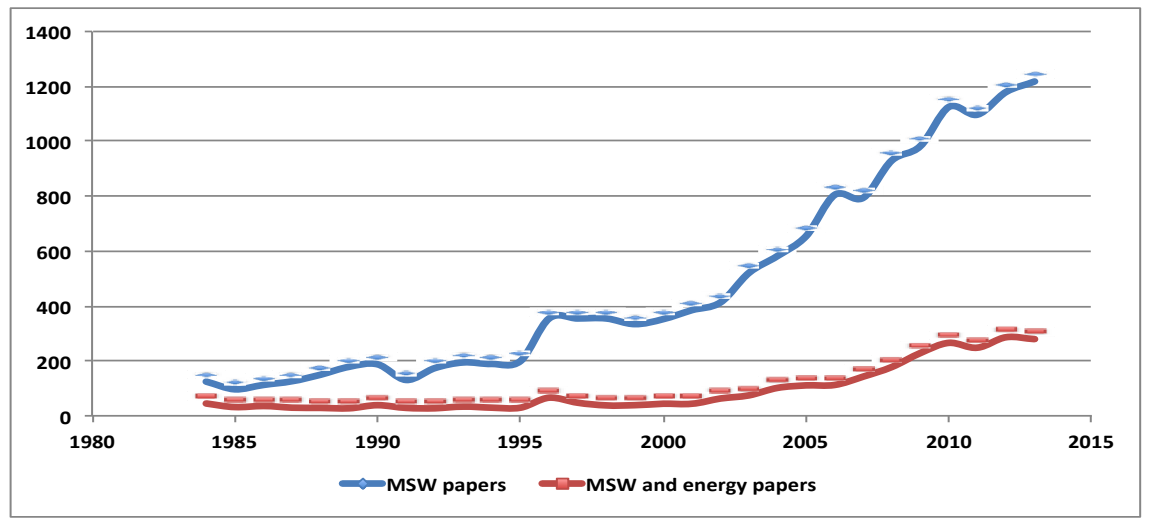

Figure 1: $\quad$ Trends of the scientific production (from Scopus ${ }^{\circledR}$ ). 
MSW has been considered for many years "material to be disposed of", but thanks to the EU legislation such as directives 74/224, 75/442 and 94/62 CE, they became a resource to be exploited. These legislations have imposed the reduction, reuse, recycling and recovery of MSW. As explained in this paper, clear links to the energy generation sector are related to the last two principles.

Step by step, thanks to the development of the knowledge regarding MSW valorisation as material or energy, MSW has become a very important resource for the future. Environmental limits and indications regarding waste collection, treatment and landfilling have been developed and implemented. This aspect was enforced by a specific legislation, such as directives 156/1991, 689/1991, 62/1994 and 468/1999 CE, in which some specific action was delimited as:

- Definition of waste and management of the entire cycle;

- Standards for MSW treatment plant;

- Collection of specific fraction in order to increase recycling and reduce the hazardous aspects of MSW.

Finally specific plans for MSW management were developed in the EU. These plans must take into account the waste hierarchy above described (prevention, preparation for reuse, recycling, energy recovery) integrated by safe disposal as last option available, according to 75/439/CEE, 91/689/CEE, 99/31/CE and 2006/12/CE. The Revised Waste Framework Directive underlines the target to increase recycling, composting, reuse and valorisation of household waste, as a percentage of the total household waste equal to $50 \%$ by 2020 .

In the last years, thanks to the selective collection (SC) implementation, the residual waste (RMSW) became to be viewed as a future energy "resource" with effects on waste-to-energy strategies $[14,15]$.

The present paper wishes to contribute to a correct knowledge dissemination regarding the MSW valorisation from the energy point of view, taking into account the development of the waste-to-energy strategies in the last decades.

\section{Energy potential of MSW}

The first topic that must be taken into account in the MSW waste-to energy strategies is the energetic content of each MSW fraction. In Figure 2 the lower heating value (LHV) for each of these fractions is reported [15]. These data are very useful to set balances for multiple scenarios in order to avoid problems with materials that should be landfilled (LVH must be lower than $13 \mathrm{MJ} / \mathrm{kg}$ and the respirometric index RI must be lower than $1,300 \mathrm{mg}_{\mathrm{O} 2} \mathrm{~kg}^{-1} \mathrm{TS}^{-1}$ ) [16, 17]. In general, where low-medium income characterises the local economy, LHV of MSW can be around 6-7 MJ/kg. On the contrary, when the economic development has caused an increase in the light packaging content of MSW, the resulting LHV can reach also $13 \mathrm{MJ} / \mathrm{kg}$. Of course for a complete view also SC must be taken into account. From the quantitative point of view it is clear that a transition from a scenario of SC with an efficiency of 35\% to another with $65 \%$ involves almost a halving of the stream of RMSW. When this happened, an accurate analysis of the available MSW treatment options must be developed [18]. 


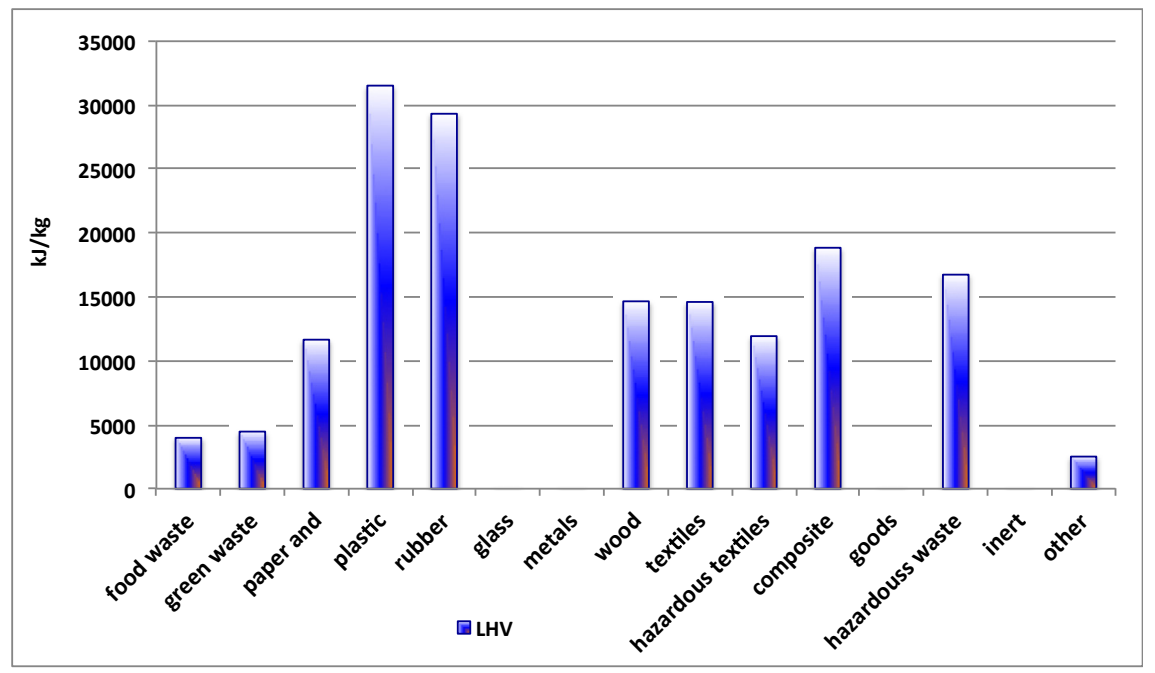

Figure 2: LHV of each MSW fraction.

It must not be forgotten, also, that a proper management of MSW must be based also on initiatives that contrast the general trend of increasing of MSW generation (per-capita production). This cannot be confused with the effect of international economic crises that can affect the buying power of people (and the consequent waste generation).

From the qualitative point of view, two aspects can be pointed out and are described below:

$>$ The first one relates to the decreasing percentage of the organic fraction in the RMSW. This aspect is due on the one hand to the increase of the use of packaging, not always accompanied by an increase of $\mathrm{SC}$ of this fraction; on the other hand, the activation of organic fraction SC decreases its content in the RMSW. In the most extreme cases, where the citizens behaviour is very efficient, the percentage of organic fraction in RMSW may fall below $10 \%$. It must be pointed out that some European countries have anyway a high percentage of organic fraction in their RMSW, as Romania and Bulgaria, recently entered into the European Union [17, 19].

$>$ The second one is related to a fraction emerged recently, the diapers. Their use has grown significantly in some parts of EU and the absence SC for this fraction makes their presence more relevant in RMSW, where their percentage may overcome in the most extreme cases even $10 \%$.

The energy exploitability ratio is presented in Figure 3 where it is clear that in general the higher is $\mathrm{SC}$, the lower is the energy exploitability rate, as a consequence of the segregation of waste fractions with a positive energy content (plastics, paper and cardboard in particular). Data refer to a real case study in the North-East of Italy [14]. In this area the efficiency of SC changed dramatically in about 20 years, thanks to the enforcement of the EU directives on waste management. 


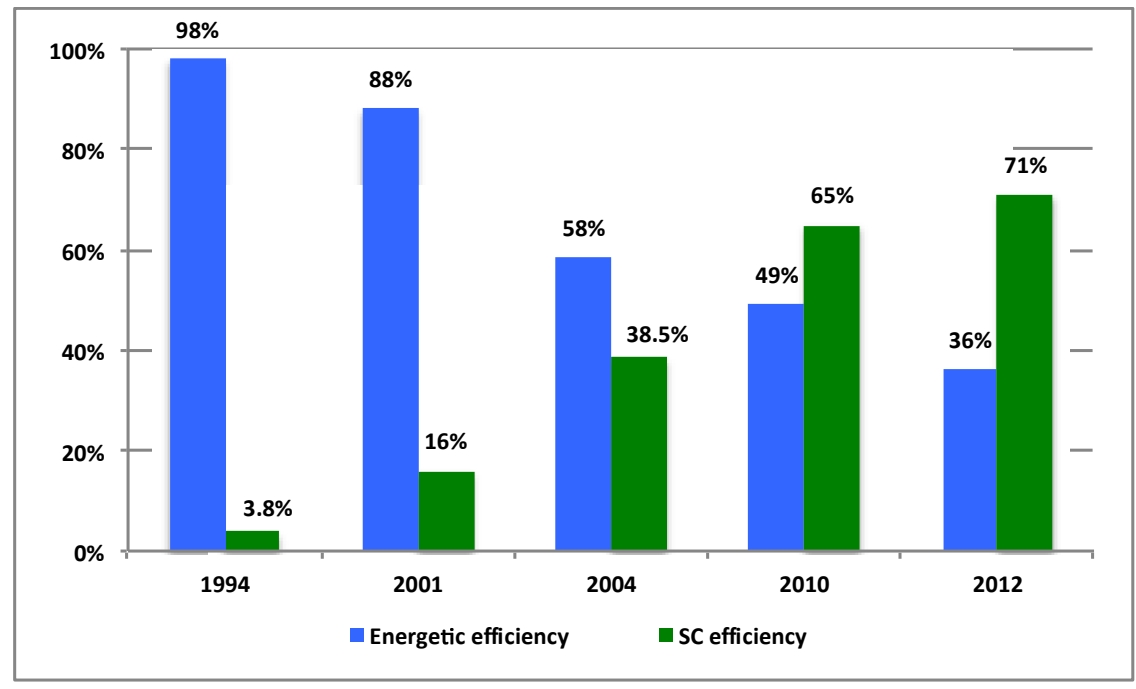

Figure 3: Energy exploitability (RMSW vs. MSW) and SC efficiency.

\section{SC to energy}

In the last century, energy valorisation in the MSW management changed considerably moving from a scenario where landfill was the central option seen like a reactor for biogas production, to a scenario where thermal treatment environmental friendly is seen as the main a waste to energy option. This evolution was also guided by the SC efficiency increase. In Figure 4 the role of $\mathrm{SC}$ in the frame of energy valorisation of MSW is reported.

Some considerations can be made referring to the material streams of Figure 4:

Biogas is generated by anaerobic digesters that take advantage from the high quality of source separation that can be reached when citizens collaborate efficiently; the amount of biogas can reach $150 \mathrm{~m}^{3} / \mathrm{t}$ of food waste, with about $60 \%$ of methane content; a deeper analysis of the role of biogas is presented below in this paper;

$>$ Paper and cardboard recycling generates residues that have a high energy content; their exploitation can be made in together with RMSW in authorised waste to energy plants; alternatively, these residues can be treated alone or with RMSW, in order to produce refuse derived fuel (RDF) to be valorised as industrial fuel;

$>$ Plastic recycling generates a significant secondary stream that cannot be easily valorised as material; the fate of these residues is similar to the previously described one;

$>$ Energy valorisation from expired medicaments is made for minimising the impact on the environment; its contribution to the energy exploitation of MSW is negligible (the collected mass is less than $0.1 \%$ of the overall amount of MSW). 


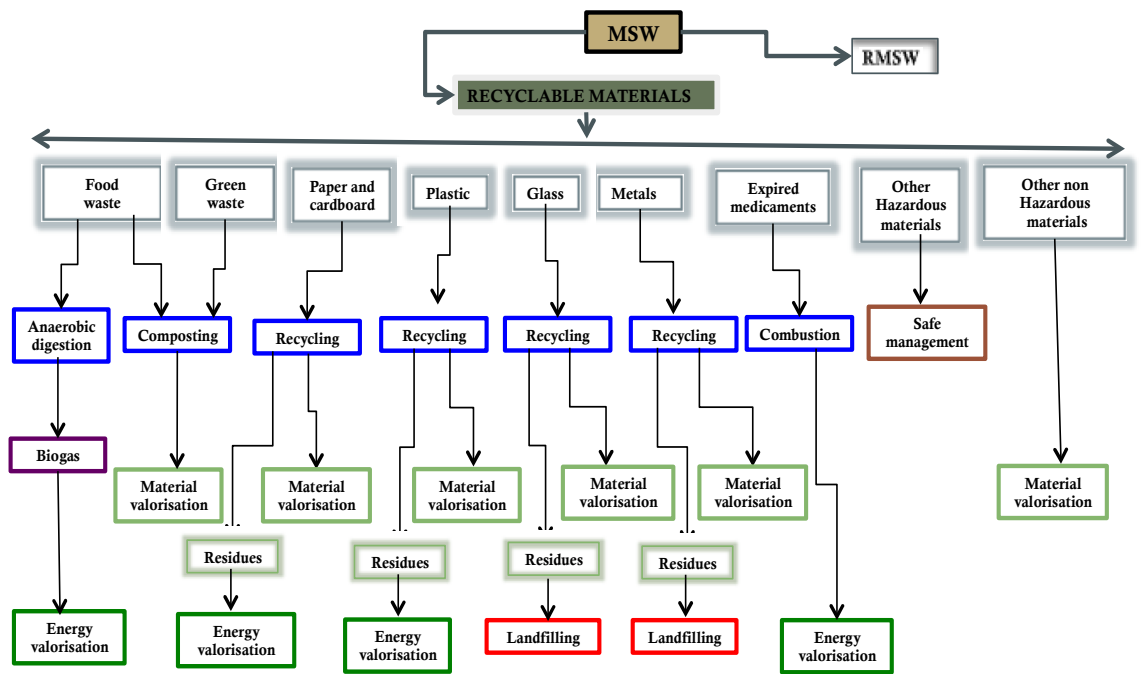

Figure 4: SC streams and energy valorisation.

In Figure 5 some details on the evolution of the MSW organic fraction (OFMSW) exploitation in the last decades is presented according to the EU vision. When landfilling without pre-treatment was dominant in the sector (before the Directive 1999/31/CE) OFMSW significantly contributed to the biogas generation from a landfill, but only about $50 \%$ of its amount could be exploited because of fugitive emissions. The introduction of pre-treatment as compulsory option before landfilling (through the above mentioned Directive) supported the initiatives of OFMSW SC; the following introduction of economic incentives for the generation of electricity from OFMSW (food waste) moved the

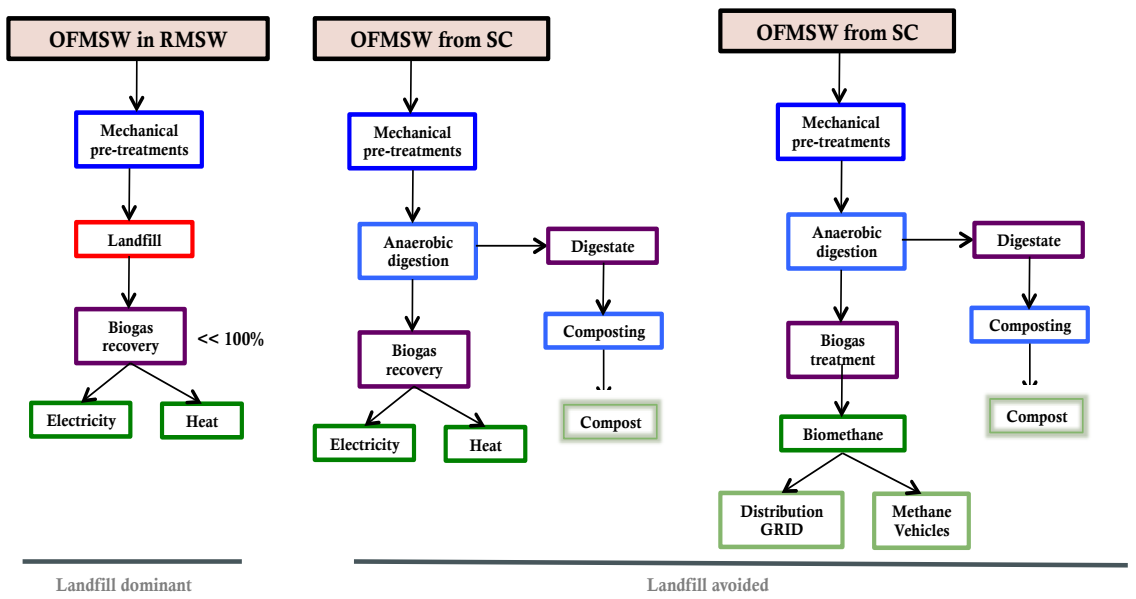

Figure 5: OFMSW management evolution. 
sector from direct composting to anaerobic digestion in dedicated reactors that can guarantee $100 \%$ of biogas collection.

The exploitation of biogas (adequately cleaned) has remained the same: cogeneration of electricity and heat thanks to the adoption of an engine coupled with an alternator.

In the next future a third scenario is expected to emerge: substitution of the engine approach by a biogas treatment aimed to the production of methane to be injected in the natural gas grid or to be used as fuel for methane vehicles.

The Directive that has opened this pathway is 2009/73/CE. What is clear is that OFMSW SC allows avoiding landfilling with environmental advantages (the greenhouse gas impact in terms of equivalent $\mathrm{CO}_{2}$ that fugitive emissions of methane have on the environment are reduced to zero).

\section{RMSW to energy}

To understand some differences between the options available for the management of RMSW, three main components can be identified: water content, volatile solids (partially biodegradable) and inert (non-volatile solids). The biodegradable solids can be also divided into quickly, medium and slowly biodegradable solids [16]. The organic part of the microorganisms present in the MSW gives a (small) contribution basically to the biodegradable solids. This characterization is useful for the understanding of the following processes.

Combustion is the thermochemical process for RMSW more consolidated and therefore more widespread. In the Nineties, in EU and EU-like regions, it had to undergo heavy changes in the design/management in order to improve its impact on the environment. The trend of combustors is towards systems able to treat RMSW with a high LHV [20]. This is related to the increase of LHV of RMSW depending on SC and MSW composition evolution. To this concern, in recent years the water-cooled grate has been developed. The increase of SC of noncombustible fractions (rich in non-volatile solids, NVS) causes a decrease in slag generation (basically composed of NVS). The percentage of slag is going down to $20 \%$ of the input whilst twenty years ago this value was $30 \%$ in most of the EU countries. The optimization of the combustion conditions in modern systems guarantees a reduced presence of volatile solids (VS) in the slag.

One aspect presently discussed concerns the possibility to use the remediation of uncontrolled landfills to recover combustible materials, otherwise not exploited [21]. In any case, the most important aspect concerns the value of the produced energy. The current growth in the cost of crude oil seems to make this strategy more attractive.

Gasification is a thermochemical process of partial oxidation in substoichiometric conditions that converts VS into a combustible gas (syn-gas). This gas can be directly exploitable (after adequate treatment) in cycles of cogeneration. In some configurations, the output is not a conventional slag but is a vitrified product as a consequence of an integrated process at high temperature [22]. In the sector of MSW, gasification is generally proposed coupled with RDF generation. 
Pyrolysis is an endothermic process developed in reducing conditions (in extreme cases in absence of free oxygen) that converts VS in three streams: syngas, exploitable directly (after treatment) in cycles of co-generation, fuel oil and combustible solid matrix. The water contained in the input can take part to the reactions. Some pre-treatments avoid the presence of inert in the combustible solid matrix (char). Parts of NVS go out anyway as fly ash, resulted from the purification of syn-gas. In some configurations NVS are vitrified through an integrated process [23].

Integrated thermal plants: there are different kinds of combined processes, as pyrolysis + combustion, combustion + gasification or pyrolysis + gasification. The aim of these options is to improve the energy and the environmental balance compared to conventional solutions [24]. These options are of interest particularly in countries where the different logics, compared to the European targets, concern the value given to the generated electricity is low (as national strategy) and high to the containment of space.

Aerobic mechanical - biological treatments: talking of RMSW, it can be noticed a comparison between bio-drying, usually performed ad single stream process, and bio-stabilization, a double stream process, characterised by a preliminary screening stage. This screening divides the waste in "dry" and "wet" streams. In terms of process, the bio-drying (process without water addition) aims to evaporate the highest amount of moisture of RMSW with the lowest consumption of biodegradable VS [25]. On the contrary, the bio-stabilization (process with water addition) consumes the highest amount of putrescible VS (those rapidly and medium biodegradable) [26]. It must be underlined the fact that the process of bio-drying is normally followed by a post-treatment of separation of glass, metals and inert (recyclable NVS) in order to produce fuels different from the qualitative point of view. These fuels are derived from waste (RDF with different quality) and can be used in various contexts (co-combustion in cement works or power stations, combustion in dedicated plants, etc.). The recent evolution of the RDF sector led to the introduction of the concept of Solid Recovered Fuel (SRF) [11, 27]. On the contrary, the bio-stabilization has been always seen as a pre-treatment for landfilling that becomes mandatory according to the latest regulations. Anyway the new regulations take into account both the LHV and the respirometric index for the pre-treated waste (parameter which gives information on the residual biodegradability of the pre-treated material) $[11,27]$. If the bio-stabilization is inserted in a separate stream facility, a parallel production of SRF will exist [28]. It must be taken into account also that a complete bio-stabilization requires energy consumption and processing time longer than bio-drying. Indeed bio-drying can be performed in about two weeks while bio-stabilization needs even a few months [29].

Anaerobic mechanical - biological treatments: this solution is less widespread than the aerobic ones. The reason concerns the difficulty of management caused by the presence of non-biodegradable materials in the RMSW. The most interesting aspect of this option is the production of biogas with a significant content of methane. Its adoption is very limited in well- 
organised realities because OFMSW SC strongly reduces the potential of biogas generation.

Figure 6 presents the scheme adopted in many EU countries for managing MSW before the introduction of the Directive 1999/31/CE: landfilling characterised the sector; waste to energy plants played often a secondary role even if they could reduce the need of landfill volumes; RDF production for partial coal substitution in industrial plants was not well developed in EU also because of a regulation to be optimised yet; the advantage of putting to zero the need of landfill when RDF was used in a cement factory was not fully exploited also because of the difficulty of local acceptance of this approach. One of the worrying among the population concerns the different approach in constructing the off-gas treatment line in the sector of cement, compared to the one of plants dedicated to RMSW. The same combustion plants had many troubles to be accepted because of their low environmental performances before the recent regulations.

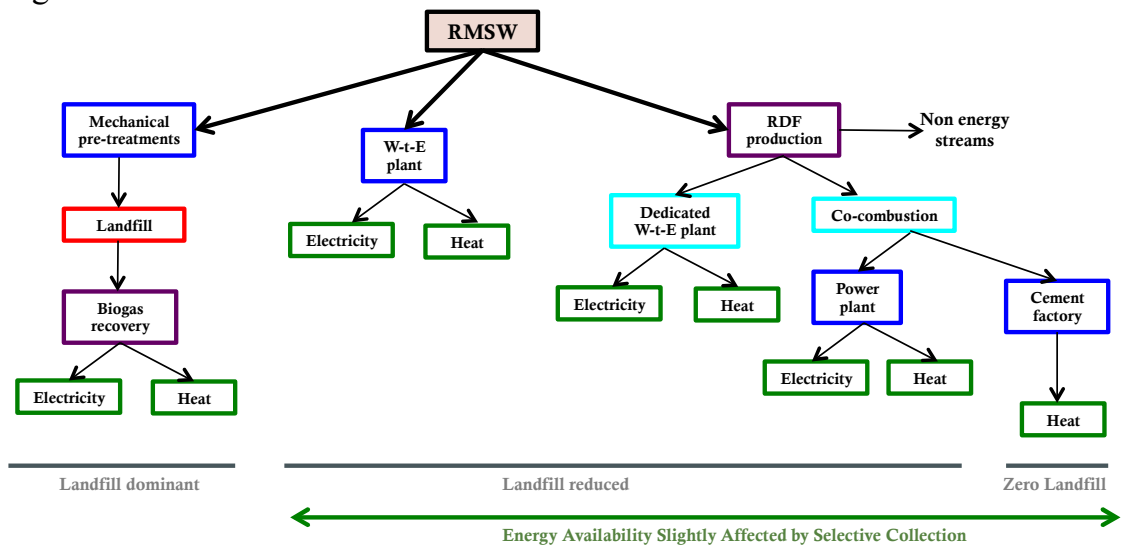

Figure 6: $\quad$ RMSW management in EU before Directive 1999/31/CE.

The adoption of the Directive 1999/31/CE changed this scenario, as explained in Figure 7, bio-stabilization cannot reduce significantly the ratio output/input (as a consequence, when this process is adopted, landfill is still prevalent) but the higher costs of this option move the choices towards other options all related to energy recovery. In particular:

$>$ The latest conventional combustion plants (based on the concept of grate) demonstrated that a net generation of electricity can reach a value of $30 \%$; the co-generated heat can be exploited locally thanks to district heating.

$>$ Concerning dedicated waste-to-energy plants fed by SRF, the expected development of pyrolysis and gasification with integrated treatment of slag should strongly decrease the need of landfill volumes.

$>$ Co-combustion of SRF should take advantage of the recent regulation that gives more guarantees both to the producers and to the users.

$>$ Energy availability is affected by high percentages of SC: a part of the streams sent to recycling is made by combustible materials. 


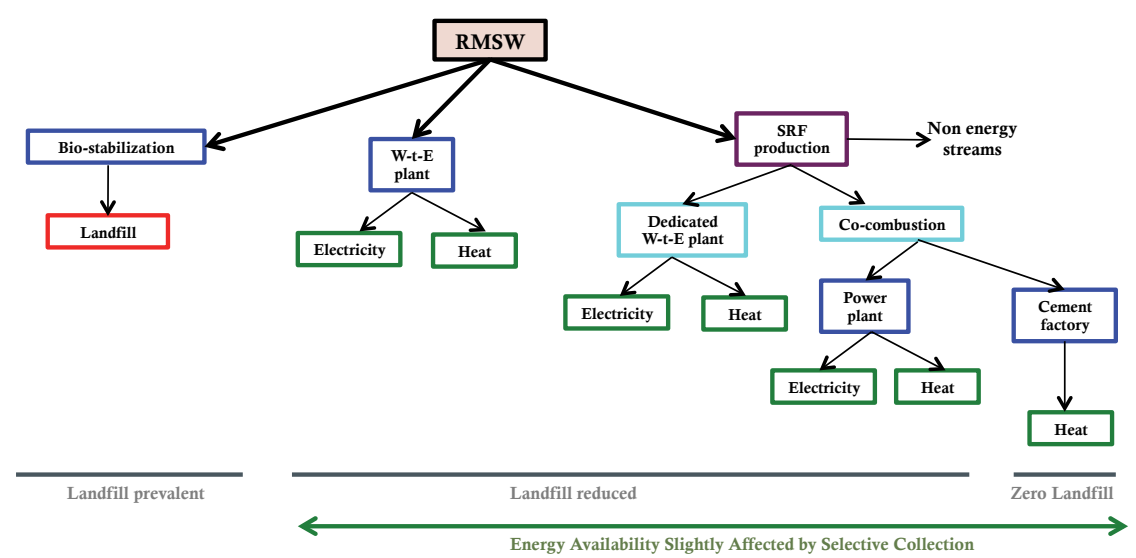

Figure 7:

RMSW management in EU after Directive 1999/31/CE.

\section{Energy availability trend}

The energy availability from MSW depends on many factors: energy content of MSW, amount of energy diverted by SC (plastics, paper and cardboard, etc.), amount of OFMSW sent to energy recovery through SC, energy content left in the RMSW, energy efficiency of the process adopted for the valorisation of RMSW (basically the co-generation efficiency) [6, 30, 31]. OFMSW anaerobic digestion and RMSW thermochemical treatment play a role that depends also on the local demand of energy. A simplified analysis can help to understand this role, as reported in Figure 8, referring to a region in the North of Italy [14] with about half a million inhabitants.

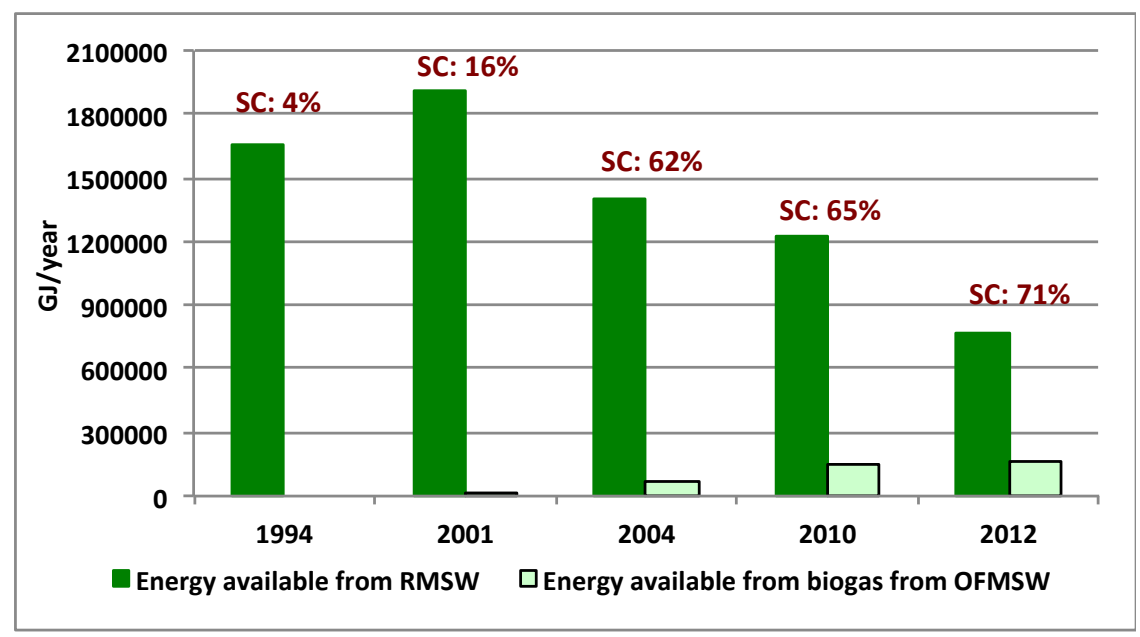

Figure 8: Example of energy availability evolution from collected RMSW and OFMSW. 
From this case study it can be noticed that:

$>$ The evolution of the composition of MSW towards higher contents of light packaging went on late in the 90s; indeed, in spite of a higher SC that diverted also a part of MSW energy, the amount of overall RMSW energy increased thanks to the increases of MSW generation and of $\mathrm{LHV}_{\mathrm{MSW}}$;

$>\mathrm{SC}$ effects seem to be against energy recovery; in reality this effect concern the possibility to generate energy in plants dedicated to waste; indeed it must be taken into account that SC can save energy in the industrial processes of product generation.

The potential electrical generation from RMSW combustion and OFMSW anaerobic digestion can be assessed taking into account an efficiency of $25 \%$ and of $40 \%$ respectively. Developing the calculation it can be demonstrated that the role of the MSW sector is significant even if he cannot cover the whole demand as demonstrated recently in the literature [13]. Concerning the availability of heat from co-generation, a value of about $60 \%$ [13] of the energy availability can be assumed for RMSW combustion, whilst anaerobic digestion uses its heat for heating the reactor. This amount covers virtually only a small part of the needs.

\section{Conclusions and outlooks}

The scenarios of energy recovery presented in this paper demonstrate that the sector of MSW is evolving towards a multi-stream management with OFMSW and RMSW that offer the most interesting opportunities of exploitation.

Concerning OFMSW, the collaboration of citizens is compulsory for obtaining a clean SC stream to be fed into the anaerobic digesters. The potential of energy that can be generated is lower than the one available from RMSW, but the production of compost after post-treatment of the digestate constitutes an opportunity to add Carbon and other substances to the soil. RMSW to energy is evolving from direct combustion to alternative processes. This evolution is also related to the development of the concept of SRF that can guarantee an homogeneous and stable input. The per-capita energy demand cannot be fully covered by the MSW exploitation, but the contribution of this sector cannot be considered negligible.

\section{Acknowledgements}

The author wishes to acknowledge PAT (Provincia Autonoma di Trento Autonomous Province of Trento, Italy) and Mr. Zatelli, in particular, for the support in data availability.

\section{References}

[1] Sakai S., Sawell S:E., Chandler A.J., Eighmy T.T., Kosson D.S., Vehlow J., Van der Sloot H.A., Hartlen J., Hjelmar O., World trends in the municipal waste management, Waste Management, 16(5-6), 341-350, 1996. 
[2] Saskalopoulos E., Badr O., Probert S.D., An integrated approach to municipal solid waste management, Resource conservation and recycling, 24(1), 33-50, 1998.

[3] Oung K.L., Wong C.P., A review of the current and future technologie for solid waste, Environmental Protection Bulletin, 71, 2-11, 2001.

[4] Cleary J., Life cycle assessments of municipal solid waste management systems: A comparative analysis of selected peer-reviewed literature, Environment International, 35(8), 1256-1266, 2009.

[5] Rada E.C., Istrate I.A., Ragazzi M., Trends in the management of the Residual Municipal Solid Waste, Environmental Technology, 30(7), 651661, 2009.

[6] Ionescu, G., Rada, E.C., Ragazzi, M., Marculescu, C., Badea, A., Apostol, $\mathrm{T}$., Integrated municipal solid waste scenario model using advanced pretreatment and waste to energy processes. Energy Conversion and Management 76, 1083-1092, 2013.

[7] Santibañez-Aguilar, J.E., Ponce-Ortega, J.M., Betzabe González- Campos, J., Serna-González, M., El-Halwagi, M.M., Optimal planning for the sustainable utilization of municipal solid waste. Waste Management 33(12), 2607-2622, 2013.

[8] Haley C.A.C., Energy recovery from burning municipal solid wastes: A review, Resources, Conservation and Recycling, 4(1-2), 77-103, 1990.

[9] Ryu C., Sharifi V.N., Swithenbank J., Thermal waste treatments for sustainable energy, Proceedings of the Institution of Civil Engineers: Engineering Sustainability, 160(3), 133-140, 2007.

[10] Garg A., Smith R., Hill D., Simms N., Pollard S., Wastes as co-fuels: The policy framework for solid recovered fuel (SRF) in Europe, with UK implications, Environmental Science and Technology, 41(14), 4868-4874.

[11] Rada E.C. and Andreottola G., RDF/SRF: which perspectives for its future in the EU, Waste Management, 32/6, pp. 1059-1060, 2012.

[12] Nigam P.S., Singh A., Production of biofuels from renewable resources, Progress in Energy and Combustion Science, 37(1), 52-68, 2011.

[13] Ionescu R.D., Ragazzi M., Battisti L., Rada E.C., Ionescu G., Potential of electricity generation from renewable energy sources in standard domestic houses, Wit Transaction on Ecology and the Environment, 176, 245-253, 2013.

[14] Rada E.C., Effects of MSW selective collection on waste-to-energy strategies, WIT Transactions on Ecology and the Environment 176, 215-223, 2013.

[15] Rada E.C., Ragazzi M. Selective collection as a pretreatment for indirect solid recovered fuel generation, Waste Management 34(2), 291-297, 2014.

[16] Rada E.C., Ragazzi M., Venturi M., Critical analysis of two respirometric methods for solid substrates based on continuous and semi-continuous aeration, Journal of Bioremediation and Biodegradation, 3(12), 1-2, 2012.

[17] Rada E.C., Istrate I.A., Panaitescu V., Ragazzi M., Carlioru T.M., Apostol T., A comparison between different scenarios of Romanian municipal 
solid waste treatment before landfilling, Environmental Engineering and Management Journal, 9(4), 589-596, 2010.

[18] Ragazzi M., Rada E.C. Effects of recent strategies of selective collection on the design of municipal solid waste treatment plants in Italy, WIT Transactions on Ecology and the Environment 109, pp. 613-2620, 2008.

[19] Kyoseva V., Todorova E., Dombalov I., Pelovsky Y., Solid waste of Sofia municipality as raw material and energy resource, Journal of Environmental Protection and Ecology, 13(3), 1442-1449, 2012.

[20] Oung K.L., Wong C.P., A review of the current and future technologies for solid waste, Environmental Protection Bulletin, 71, 2-11, 2001.

[21] Bosmans A., Vanderreydt I., Geysen D, Helsen L., The crucial role of Waste-to-Energy technologies in enhanced landfill mining: A technology review, Journal of Cleaner Production, 55, 10-23, 2013.

[22] Ray R., Taylor R., Chapman C., The deployment of an advanced gasification technology in the treatment of household and other waste streams, Process Safety and Environmental Protection, 90(3), 213-220, 2012.

[23] Ionescu G., Marculescu C., Badea A., Alternative solutions for MSW to energy conversion, UPB Scientific Bulletin, Series C, 73(3), 243-254, 2011.

[24] Ragazzi M., Rada E.C., Multi-step approach for comparing the local air pollution contributions of conventional and innovative MSW thermochemical treatments, Chemposphere, 89(6), 694.701, 2012.

[25] Rada E.C., Ragazzi M., Badea A., MSW Bio-drying: Design criteria from A 10 years research, UPB Scientific Bulletin, 74(3), 209-216, 2012.

[26] He P., Shao Z., Zhang D., Shao L., Changes of pollution potential during biostabilization of municipal solid waste as pretreatment prior to landfill, Journal of Tongji University, 37(6), 791-795, 2009.

[27] Ragazzi M., Rada E.C., RDF/SRF evolution and MSW bio-drying, WIT Transactions on Ecology and the Environment, 163, 199-208, 2012.

[28] Adani F., Tambone F., Gotti A., Biostabilization of municipal solid waste, Waste Management, 24(8), 775-783, 2004.

[29] Ragazzi M., Rada E.C., Panaitescu V., Apostol T., Municipal solid waste pre-treatment: a comparison between two dewatering options, WIT Transactions on Ecology and the Environment, 102, 943-949, 2007.

[30] Consonni S., Giugliano M., Massarutto A., Ragazzi M., Saccani C., Material and energy recovery in integrated waste management systems: project overview and main results, Waste Management, 31(9-10), 2057 2065, 2011.

[31] Rao M.S., Singh S.P., Bioenergy conversion studies of organic fraction of MSW: Kinetic studies and gas yield-organic loading relationships for process optimization, Bioresource Technology, 95(2), 173-185, 2004. 